\title{
Effect of intracoronary adenosine on ergonovine- -induced vasoconstricted coronary arteries
}

\author{
Jun-Hyok $\mathrm{Oh}^{1}$, Seunghwan Song ${ }^{2}$, Changhoon $\mathrm{Kim}^{3}$, Jinhee Ahn ${ }^{1}$, Jin Sup Park ${ }^{1}$, \\ Hye Won Lee ${ }^{1}$, Jung Hyun Choi ${ }^{1}$, Han Cheol Lee ${ }^{1}$, Kwang Soo Cha ${ }^{1}$, Taek Jong Hong ${ }^{1}$ \\ ${ }^{1}$ Department of Cardiology, Medical Research Institute, \\ Pusan National University Hospital, Busan, South Korea \\ ${ }^{2}$ Department of Thoracic and Cardiovascular Surgery, Medical Research Institute, \\ Pusan National University Hospital, Busan, South Korea \\ ${ }^{3}$ Department of Preventive Medicine, Medical Research Institute, \\ Pusan National University Hospital, Busan, South Korea
}

\begin{abstract}
Background: This study aimed to evaluate the effect of adenosine on epicardial coronary artery diameter during ergonovine provocation testing.

Methods: A total of 158 patients who underwent an ergonovine provocation test with intracoronary adenosine injection between 2011 and 2014 were selected. Patients were divided into four groups based on the severity of percent diameter stenosis following intracoronary ergonovine administration: Group 1 , induced spasm < 50\%; Group 2, 50-89\%; Group 3, 90-99\%; and Group 4, total occlusion.

Results: Spasm positivity was observed in 44 (27.8\%) cases in the study population (mean age, $57.4 \pm$ \pm 10.7 years). Intracoronary adenosine increased the diameter of the ergonovine-induced epicardial artery by $0.51 \pm 0.31 \mathrm{~mm}, 0.73 \pm 0.39 \mathrm{~mm}, 0.44 \pm 0.59 \mathrm{~mm}$, and $0.01 \pm 0.04 \mathrm{~mm}$ in Groups 1, 2, 3, and 4, respectively. Subsequent administration of nitroglycerin further increased vessel diameter by $0.49 \pm 0.28 \mathrm{~mm}, 0.93 \pm 0.68 \mathrm{~mm}, 2.11 \pm 1.25 \mathrm{~mm}$, and $2.23 \pm 0.69 \mathrm{~mm}$ in Groups 1, 2, 3, and 4, respectively. The ratios of adenosine-induced diameter to reference diameter were significantly lower in patients with spasm positive results (0.68 [0.59-0.76] vs. 0.18 [0.00-0.41], $p<0.001$ in the study population; 0.60 [0.54-0.67] vs. 0.40 [0.27-0.44], $p<0.001$ in Group 2) with the best cut-off value of 0.505 (sensitivity 0.955, specificity 0.921).
\end{abstract}

Conclusions: Intracoronary administration of adenosine dilated the ergonovine-induced vasoconstricted epicardial coronary artery. The ratio of adenosine-induced diameter to reference diameter was significantly lower in patients with spasm positive results. (Cardiol J 2019; 26, 6: 653-660)

Key words: ergonovine, adenosine, vasospasm, coronary artery, angina

\section{Introduction}

Coronary artery spasm has been recognized as the main pathomechanism for variant angina, as well as acute myocardial infarction and sudden cardiac death in severe cases [1-4]. It has been shown to be correlated with early atherosclerosis and has a higher prevalence in Asian populations than Caucasians [5, 6]. Ergonovine maleate is a weak vasoconstrictor, and induces a vasoconstrictor response in susceptible epicardial coronary arteries. This response is mediated by endothelium-independent smooth muscle hyperconstriction and more pronounced with endothelial dysfunction

Address for correspondence: Dr. Taek Jong Hong, Department of Cardiology, Medical Research Institute, Pusan National University Hospital, 179 Gudeok-ro, Seo-gu, Busan, 49241, South Korea, tel: +82-51-240-7794, fax: +82-51-240-7796, e-mail: jhoh724@hanmail.net

Received: $14.02 .2018 \quad$ Accepted: 30.06 .2018 
$[7,8]$. In patients with confirmed variant angina, ergonovine provocation can induce coronary artery spasm at the same site where spontaneous spasm was observed with high diagnostic sensitivity and specificity $[9,10]$. Adenosine is an endogenous neurotransmitter that can be synthesized by de novo purine biosynthesis or produced by degradation of 5'-adenosine triphosphate and 5'-adenosine monophosphate $[11,12]$. Its biologic effects include inhibition of platelet aggregation, modulation of the inflammatory response, negative chronotropic and dromotropic effects, and induction of coronary vasodilation, predominantly affecting microvessels $<150 \mu \mathrm{m}$ in diameter [13]. Due to its potent vasodilator effect in coronary microvessels, it has been the most widely used drug to achieve hyperemia while measuring fractional flow reserve (FFR) in the coronary artery bed. However, the effect of adenosine on the ergonovine-induced vasoconstricted epicardial coronary artery has not been elucidated. The purpose of this study was to investigate the response of ergonovineinduced vasoconstricted epicardial coronary artery to adenosine and to clarify the suitability of FFR measurement using intracoronary adenosine on that vasocontricted epicardial coronary artery.

\section{Methods}

\section{Study population}

From June 2011 to June 2014, the spasm provocation test with selective intracoronary injection of ergonovine was performed in 464 patients deemed to have variant angina. When a spasm was induced, adenosine administration into the spasm-induced coronary artery has been recommended routinely since 2011. A total of 158 patients who received intracoronary adenosine during the provocation test were identified and analyzed retrospectively. Informed consent for the test using both ergonovine and adenosine was obtained from each patient, and the study was approved by the Institutional Review Board of the hospital.

\section{Ergonovine provocation test}

The left coronary artery (LCA) and the right coronary artery (RCA) were provoked to spasm according to a standard manner recommended by the Japanese Circulation Society [14, 15]. Calcium antagonists, long-acting nitrates, and nicorandil were discontinued at least $48 \mathrm{~h}$ before the provocation test, except for as needed sublingual nitroglycerin.

Baseline coronary angiography was obtained with a 5 -French (Fr) catheter via the femoral or radial artery (57 cases), which have been the default access points since 2012 . The provocation test was performed when there was no significant stenosis ( $>75 \%$ luminal narrowing). Stepwise doses of methylerogometrine maleate (ER) (Daewon Pharm, Seoul, Korea) were selectively administered into the LCA $(10,20$, and $20 \mu \mathrm{g})$ and RCA $(10,10$, and $20 \mu \mathrm{g})$ with 3 -min intervals between each dose. RCA spasm provocation was initiated after a 5-min washout period following LCA provocation. Coronary angiograms were obtained with each ER administration or when chest pain and/or ST-segment changes occurred. A selective dose of adenosine, $60 \mu \mathrm{g}$ for the LCA and $40 \mu \mathrm{g}$ for the RCA corresponding to the standard dose for FFR measurement, was injected into the coronary artery which had the maximum induced spasm and was followed by repeated coronary angiogram [16]. Intracoronary nitroglycerin was then administered until the spasm was entirely relieved and final coronary angiogram was performed.

A positive response was defined as transient greater than $90 \%$ diameter stenosis on coronary angiography, regardless of symptoms or sign of ischemia, or greater than $70 \%$ diameter stenosis with ischemic electrocardiography (ECG) changes and/or chest pain.

\section{Quantitative angiographic analysis}

End-diastolic cineframes in the same projection were selected and analyzed separately by two independent investigators using QCA software (Xcelera, Philips Medical Systems, the Netherlands). The coronary artery luminal diameter was measured in millimeters using a contrast-filled catheter as the calibration source. The most severely narrowed segment was termed the spasm segment and its diameter in response to ER, adenosine, and nitroglycerin were termed Diameter ${ }_{\mathrm{ER}}$, Diameter $_{\text {Ade }}$, and Diameter ${ }_{\text {Nit }}$, respectively. When control angiograms of the LCA were obtained after a full-dose provocation of the RCA, the diameter was noted as Diameter Control. $_{\text {. Reference diameter }}$ (Diameter ${ }_{\text {Ref }}$ ) was defined as the average of the diameter of the nearest normal-looking segments before and after the spasm segment. The degree of induced spasm was calculated as [1 - (Diameter ${ }_{\mathrm{ER}} /$ $/$ Diameter $\left.\left._{\text {Ref }}\right)\right] \times 100$ and noted as $\%$ Spasm. The differences in diameter between Diameter $\mathrm{ER}_{\mathrm{ER}}$ and Diameter $_{\text {Ade }}$, and between Diameter Nit $_{\text {Nit }}$ and Diameter ${ }_{\text {Ade }}$ were noted as $\Delta$ Adenosine and $\Delta$ Nitroglycerin, respectively. The sum of the change in diameter between Diameter $\mathrm{ER}_{\mathrm{ER}}$ and Diameter Nit $_{\mathrm{Nit}}$ was calculated as $\Delta$ Sum $=$ Diameter $_{\text {Nit }}-$ Diameter $_{\mathrm{ER}}$. 


\section{Statistical analysis}

For the purpose of this study, patients were categorized into four groups according to the \%Spasm as follows: Group 1, 0-50\%; Group 2, 50-90\%; Group 3, 90-99\%; Group 4, total occlusion. The normality of continuous data was tested using the Kolmogorov-Smirnov test. Skewed variables were analyzed after logarithmic or power transformation, accordingly. Continuous variables are expressed as the mean \pm standard deviation (SD) or median (interquartile range) and assessed with the Student t-test or Mann-Whitney U test. Within-group comparisons were performed with repeated measures analysis of variance (ANOVA) with post hoc analysis using Bonferroni corrections. Comparison of the mean values among groups was made using one-way ANOVA. Trends were assessed using the linear-by-linear association $\chi^{2}$ test or the linear term in ANOVA. Categorical variables are presented as frequencies and compared using the Fisher exact probability test. The receiver-operating curve was created to draw the best cut-off value of the ratio of Diameter Ade $_{\text {d }} /$ $/$ Diameter $_{\text {Ref }}$ and discriminate the result of the spasm test. Correlations between variables were tested using linear regression analysis. Multivariate linear regression analysis was applied to identify the predictors for the Diameter Ade $_{\text {d }} /$ Diameter $_{\text {Ref }}$ ratio. Statistical significance was defined as $\mathrm{p}<$ $<0.05$. All statistical calculations were performed using the SPSS software version 17.0 (IBM SPSS Inc., Chicago, IL).

\section{Results}

\section{Clinical characteristics}

A total of 158 patients were included in the study and categorized into the following four groups: Group 1, 50 (32.9\%) patients; Group 2, 82 (51.9\%) patients; Group 3, 9 (5.7\%) patients; and Group 4, 15 (9.5\%) patients. The mean age was $57.4 \pm 10.7$ years without significant differences among groups (Table 1). There was a tendency for increasing male population $(\mathrm{p}<0.001)$ and current smoking $(\mathrm{p}=0.037)$ from Groups $1-4$. No significant difference was seen in the incidence of diabetes mellitus, hypertension, hyperlipidemia and clinical presentations between groups.

Methylerogometrine maleate provocation test was performed via the radial artery in $57(36.1 \%)$ and femoral artery in 101 (63.9\%) patients (Table 2$)$. Overall, $44(27.8 \%)$ patients had a positive response. There were no provocation-related adverse events including death, myocardial infarction, stroke, or bleeding that required a procedure or transfusion. There was 1 case of contrast allergy, and 3 cases of self-limiting and transient bradycardia in response to adenosine.

\section{Changes in vessel diameter}

The investigated vessels were the left anterior descending artery (LAD) and its branches in $60(38.0 \%)$ patients, left circumflex artery (LCX) and its branches in 12 (7.6\%), RCA and its branches in $82(51.9 \%)$, and left main in $4(2.5 \%)$ patients. Two representative cases are depicted in Figure 1. The cumulative dose of injected ER was significantly lower in Groups 3 and 4, compared with the other groups. Although Diameter ${ }_{\text {Ref }}$ was similar between groups, Diameter ${ }_{\mathrm{ER}}$, Diameter $\mathrm{Dde}_{\mathrm{Ad}}$, and Diameter ${ }_{\text {Nit }}$ progressively decreased from Group 1 to Group 4.

Adenosine was administered into the same coronary artery immediately after the angiogram of the last dose of ER in 114 cases (32 LCA, 82 RCA). In the remaining 44 cases, adenosine was injected into the LCA after a full provocation of the RCA, where control angiograms of the LCA revealed an increase in diameter of the vessel (Diameter $\mathrm{ER}_{\mathrm{ER}}$, $1.65 \pm 0.75 \mathrm{~mm}$; Diameter $_{\text {Control }}, 1.90 \pm 0.75 \mathrm{~mm}$ ). Adenosine further dilated the vessel (Diameter ${ }_{\text {Ade }}$, $2.31 \pm 0.76 \mathrm{~mm})$, but lesser than Diameter ${ }_{\text {Nit }}$ $(2.82 \pm 0.82 \mathrm{~mm})$ in those patients. Overall, the increase in diameter with adenosine ( $\triangle$ Adenosine) progressively decreased from Group 1 to Group 4, but the amount by nitroglycerin ( $\Delta$ Nitroglycerin) did vice versa. Adenosine did not increase the vessel diameter in Group 4 (Diameter ER $_{\text {ER }} 0.00 \pm 0.00$; Diameter $_{\text {Ade }}, 0.01 \pm 0.04$, paired t-test $\mathrm{p}=0.334$ ).

\section{Adenosine response based on test results}

All patients in Group 3 and 4 had spasm positive results using the angiographic definition, while $20(24.5 \%)$ had spasm positive results in Group 2. There was a significant increase in diameter following adenosine and nitroglycerine injection regardless of the result of the spasm test. Overall, there was a significant interaction between the pattern of diameter increase and the test result $(\mathrm{n}=158 ; \mathrm{F}[1.597,249.1]=77.271 ; \mathrm{p}<0.001)$ (Fig. 2A). There was a greater increase in diameter following adenosine injection ( $\Delta$ Adenosine) in those with spasm negative results, than in those with spasm positive results $(0.64 \pm 0.36$ vs. $0.41 \pm$ $\pm 0.50, \mathrm{p}=0.002)$. The increase in diameter following nitroglycerine ( $\Delta$ Nitroglycerin) was significantly greater in those with spasm positive results than those with spasm negative results $(1.84 \pm 0.98 \mathrm{vs}$. 
Table 1. Demographic and laboratory characteristics.

\begin{tabular}{lcccccc}
\hline & $\begin{array}{c}\text { Group 1 } \\
(\mathbf{n}=50)\end{array}$ & $\begin{array}{c}\text { Group 2 } \\
(\mathbf{n}=82)\end{array}$ & $\begin{array}{c}\text { Group 3 } \\
(\mathbf{n}=9)\end{array}$ & $\begin{array}{c}\text { Group 4 } \\
(\mathbf{n}=15)\end{array}$ & $\begin{array}{c}\text { Total } \\
(\mathbf{n}=158)\end{array}$ & P \\
\hline Age [years] & $56.7 \pm 11.7$ & $58.1 \pm 10.9$ & $60.0 \pm 7.0$ & $54.7 \pm 7.6$ & $57.4 \pm 10.7$ & 0.569 \\
Male & $23(44.2 \%)$ & $52(63.4 \%)$ & $7(77.8 \%)$ & $14(93.3 \%)$ & $96(60.8 \%)$ & 0.002 \\
BMI [kg/m²] & $23.6(21.5-25.5)$ & $24.5(23.1-26.5)$ & $25.1(23.1-28.8)$ & $23.4(22.4-26.0)$ & $24.1(22.5-26.3)$ & 0.232 \\
Hypertension & $17(32.7 \%)$ & $31(37.8 \%)$ & $7(77.8 \%)$ & $5(33.3 \%)$ & $60(38.0 \%)$ & 0.090 \\
Diabetes mellitus & $5(9.6 \%)$ & $12(14.6 \%)$ & $2(22.2 \%)$ & $4(26.7 \%)$ & $23(14.6 \%)$ & 0.265 \\
Hyperlipidemia & $35(67.3 \%)$ & $46(56.1 \%)$ & $5(55.6 \%)$ & $8(53.3 \%)$ & $94(59.5 \%)$ & 0.551 \\
Current smoking & $9(17.3 \%)$ & $28(34.1 \%)$ & $6(66.7 \%)$ & $5(33.3 \%)$ & $48(30.4 \%)$ & $0.014 *$ \\
Chest pain & $41(78.8 \%)$ & $62(75.6 \%)$ & $9(100.0 \%)$ & $13(86.7 \%)$ & $125(79.1 \%)$ & 0.393 \\
CCS grade 3 and 4 & $25(48.1 \%)$ & $41(50.0 \%)$ & $4(44.4 \%)$ & $10(66.7 \%)$ & $80(50.6 \%)$ & 0.619 \\
Syncope & $4(7.7 \%)$ & $11(13.4 \%)$ & $0(0.0 \%)$ & $0(0.0 \%)$ & $15(9.5 \%)$ & 0.370 \\
Post CPR & $1(1.9 \%)$ & $1(1.2 \%)$ & $1(11.1 \%)$ & $1(6.7 \%)$ & $4(2.5 \%)$ & 0.142 \\
SBP [mmHg] & $127.7 \pm 21.0$ & $124.4 \pm 17.1$ & $125.3 \pm 27.7$ & $122.5 \pm 16.3$ & $125.3 \pm 19.0$ & 0.718 \\
HR [bpm] & $71.7 \pm 16.0$ & $73.7 \pm 13.2$ & $69.3 \pm 16.1$ & $69.5 \pm 10.4$ & $72.4 \pm 14.1$ & 0.595 \\
TC [mg/dL] & $197.3 \pm 33.5$ & $181.1 \pm 39.0$ & $168.9 \pm 30.0$ & $190.7 \pm 69.3$ & $186.6 \pm 41.2$ & 0.080 \\
Cr [mg/dL] & $0.71(0.65-0.88)$ & $0.82(0.68-0.97)$ & $0.88(0.72-1.05)$ & $0.80(0.67-0.89)$ & $0.80(0.66-0.94)$ & 0.229 \\
Hb [g/dL] & $12.8 \pm 2.5$ & $13.7 \pm 1.6$ & $15.0 \pm 1.6$ & $14.6 \pm 1.3$ & $13.6 \pm 2.0$ & 0.001 \\
hsCRP [mg/dL] & $0.06(0.03-0.17)$ & $0.08(0.02-0.25)$ & $0.14(0.03-0.22)$ & $0.09(0.03-0.37)$ & $0.08(0.03-0.22)$ & 0.836 \\
\hline
\end{tabular}

Values are mean \pm standard deviation or median (interquartile range) or number (percentage). ${ }^{*} \mathrm{P}$ value for trend was $<0.05$. BMI - body mass index; CCS - Canadian Cardiovascular Society; CPR — cardiopulmonary resuscitation; SBP — systolic blood pressure; HR — heart rate; $\mathrm{TC}$ - total cholesterol; $\mathrm{Cr}$ - creatinine; $\mathrm{Hb}$ - hemoglobin; hsCRP — high sensitivity C-reactive protein

Table 2. Angiographic characteristics.

\begin{tabular}{|c|c|c|c|c|c|c|}
\hline & $\begin{array}{l}\text { Group } 1 \\
(n=50)\end{array}$ & $\begin{array}{l}\text { Group } 2 \\
(\mathrm{n}=82)\end{array}$ & $\begin{array}{c}\text { Group } 3 \\
(\mathrm{n}=9)\end{array}$ & $\begin{array}{l}\text { Group } 4 \\
(\mathrm{n}=15)\end{array}$ & $\begin{array}{c}\text { Total } \\
(\mathrm{n}=158)\end{array}$ & $\mathbf{P}$ \\
\hline Spasm positive & $0(0.0 \%)$ & $20(24.4 \%)$ & $9(100 \%)$ & $15(100 \%)$ & $44(27.8 \%)$ & $<0.001$ \\
\hline Radial approach & $15(28.8 \%)$ & $27(32.9 \%)$ & $6(66.7 \%)$ & $9(60.0 \%)$ & $57(36.1 \%)$ & $0.031 *$ \\
\hline \multicolumn{7}{|l|}{ Investigated vessel } \\
\hline LAD and subbranches & $15(28.8 \%)$ & $35(42.7 \%)$ & $1(11.1 \%)$ & $9(60.0 \%)$ & $60(38.0 \%)$ & 0.038 \\
\hline LCX and subbranches & $3(5.8 \%)$ & $5(6.1 \%)$ & $2(22.2 \%)$ & $2(13.3 \%)$ & $12(7.6 \%)$ & 0.185 \\
\hline RCA and subbranches & $31(59.6 \%)$ & $41(50.0 \%)$ & $6(66.7 \%)$ & $4(26.7 \%)$ & $82(51.9 \%)$ & 0.121 \\
\hline Left main & $3(5.8 \%)$ & $1(1.2 \%)$ & $0(0.05)$ & $0(0.0 \%)$ & $4(2.5 \%)$ & 0.536 \\
\hline $\begin{array}{l}\text { Cumulative dose } \\
\text { of ergonovine }[\mu \mathrm{g}]\end{array}$ & $90(90-90)$ & $90(90-90)$ & $60(40-90)$ & $30(10-55)$ & $90(90-90)$ & $<0.001$ \\
\hline Diameter $_{\text {Ref }}[\mathrm{mm}]$ & $3.46 \pm 0.74$ & $3.49 \pm 0.78$ & $3.49 \pm 0.89$ & $3.14 \pm 0.79$ & $3.45 \pm 0.77$ & 0.455 \\
\hline Diameter $_{\mathrm{ER}}[\mathrm{mm}]$ & $2.14 \pm 0.56$ & $1.12 \pm 0.42$ & $0.29 \pm 0.09$ & $0.00 \pm 0.00$ & $1.30 \pm 0.82$ & $<0.001^{*}$ \\
\hline Diameter $_{\text {Ade }}[\mathrm{mm}]$ & $2.66 \pm 0.66$ & $1.85 \pm 0.57$ & $0.73 \pm 0.61$ & $0.01 \pm 0.04$ & $1.88 \pm 0.97$ & $<0.001^{*}$ \\
\hline Diameter $_{\text {Nit }}[\mathrm{mm}]$ & $3.14 \pm 0.76$ & $2.77 \pm 0.77$ & $2.84 \pm 0.99$ & $2.25 \pm 0.67$ & $2.86 \pm 0.81$ & $0.001^{*}$ \\
\hline Diameter $_{\text {Ade }} /$ Diameter $_{\text {Ref }}$ & $0.76 \pm 0.09$ & $0.54 \pm 0.15$ & $0.22 \pm 0.20$ & $0.01 \pm 0.02$ & $0.55 \pm 0.26$ & $<0.001^{*}$ \\
\hline$\Delta$ Adenosine $[\mathrm{mm}]$ & $0.51 \pm 0.31$ & $0.73 \pm 0.39$ & $0.44 \pm 0.59$ & $0.01 \pm 0.04$ & $0.58 \pm 0.42$ & $<0.001^{*}$ \\
\hline$\Delta$ Nitroglycerin $[\mathrm{mm}]$ & $0.49 \pm 0.28$ & $0.93 \pm 0.68$ & $2.11 \pm 1.25$ & $2.23 \pm 0.69$ & $0.97 \pm 0.83$ & $<0.001^{*}$ \\
\hline$\Delta \mathrm{Sum}[\mathrm{mm}]$ & $1.00 \pm 0.42$ & $1.66 \pm 0.70$ & $2.55 \pm 0.96$ & $2.25 \pm 0.67$ & $1.54 \pm 0.78$ & $<0.001^{*}$ \\
\hline
\end{tabular}

Values are mean \pm standard deviation or median (interquartile range) or number (percentage). ${ }^{*} \mathrm{P}$ value for trend was $<0.05$. LAD - left anterior descending artery; LCX — left circumflex artery; RCA — right coronary artery 


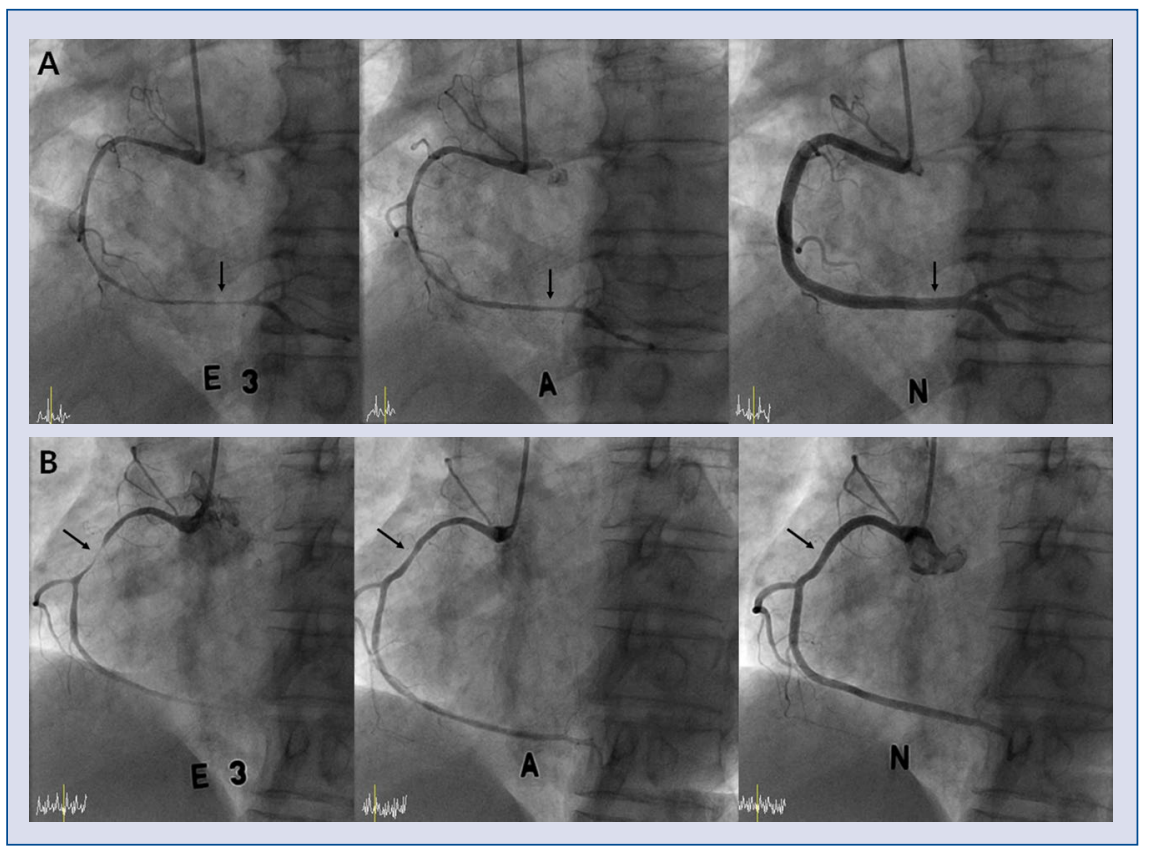

Figure 1. Coronary angiogram of representative cases. A. The sequential coronary angiogram of the right coronary artery (RCA) of an 82-year-old male. Intracoronary injection of ergonovine provokes spasm in the distal part of the RCA with a diameter of $0.60 \mathrm{~mm}(85 \%$ stenosis, arrow). Intracoronary administration of adenosine dilates it to a diameter of $0.88 \mathrm{~mm}$. A full vasodilation is achieved by nitroglycerine injection and the calculated reference vessel diameter is $3.92 \mathrm{~mm}$ resulting in the ratio of Diameter ${ }_{\text {ade }}$ to Diameter $_{\text {ref }}$ of 0.23 ; $\mathbf{B}$. The sequential coronary angiogram of the RCA of a 59-year-old female. The induced spasm is noted in the middle segment of the RCA ( $91 \%$ stenosis, arrow). Intracoronary administration of adenosine dilated it to a diameter of $1.84 \mathrm{~mm}$ with the ratio of Diameter Ade $_{\text {to }}$ Diameter $_{\text {Ref }}$ of 0.67 .

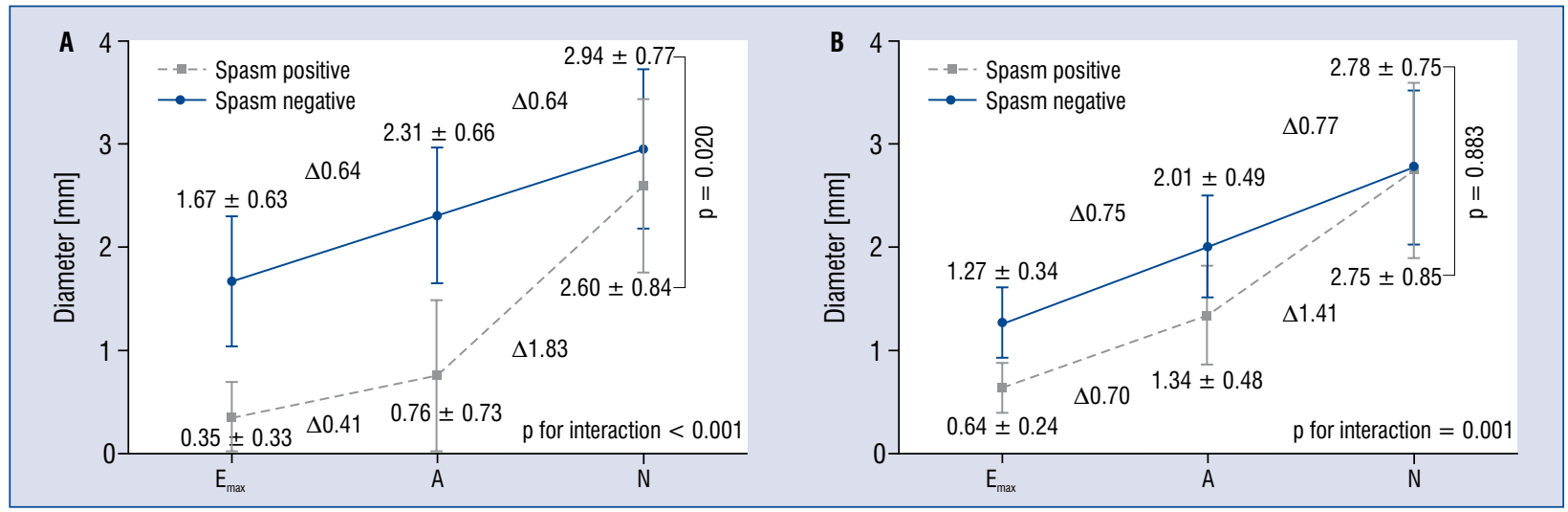

Figure 2. Mean diameter changes after ergonovine, adenosine, and nitroglycerin administration. A. Mean diameter changes in response to a maximum dose of ergonovine $\left(E_{\max }\right)$, adenosine $(A)$, and nitroglycerin $(N)$ according to the result of a spasm test in the overall study population; B. Mean diameter changes in response to the agents, respectively, in Group 2 (induced spasm between $50 \%$ and $90 \%$ ); p values for interaction between the groups with negative and positive results.

$0.64 \pm 0.44, \mathrm{p}<0.001)$. There was also a significant interaction between diameter changes and the test results in Group $2(\mathrm{~F}[1.567,125.323]=11.877$, $\mathrm{p}<0.001)$ (Fig. 2B). The $\Delta$ Adenosine of those with spasm negative results and with spasm posi- tive results were similar $(0.75 \pm 0.37$ vs. $0.70 \pm$ $\pm 0.46, \mathrm{p}=0.648$ ). However, the $\Delta$ Nitroglycerin was significantly greater in those with spasm positive results than in those with spasm negative results $(0.77 \pm 0.51$ vs. $1.41 \pm 0.89, \mathrm{p}<0.001)$. 


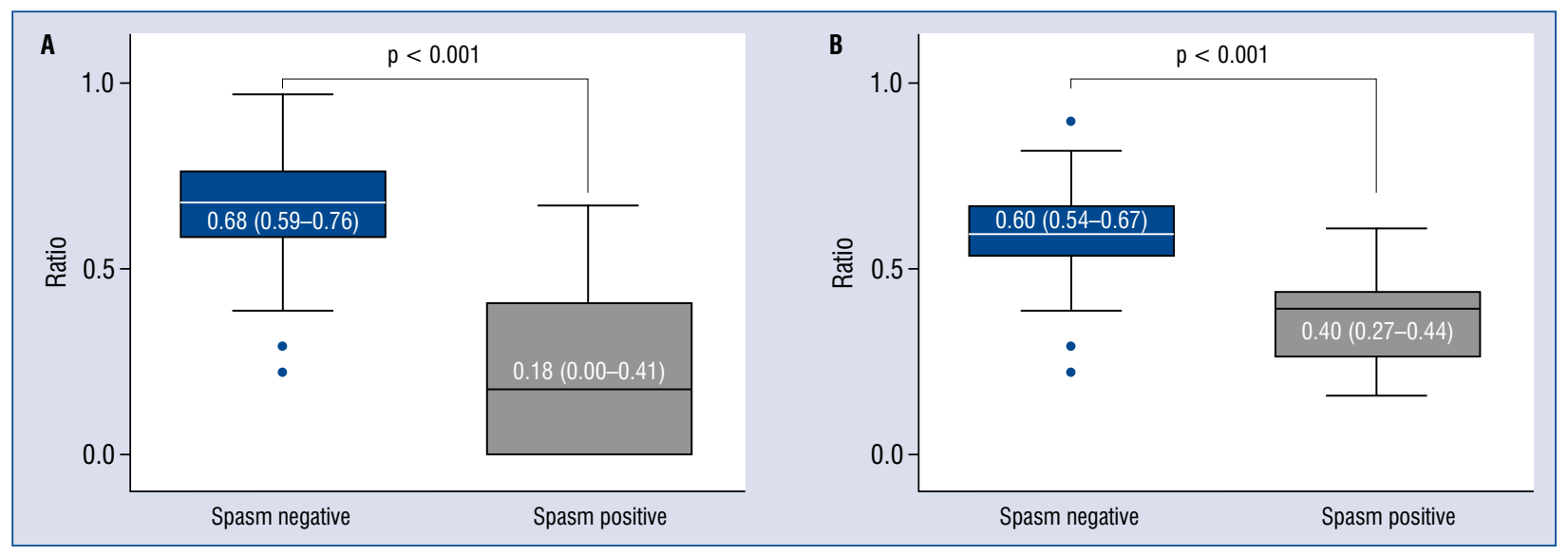

Figure 3. Box plot for the ratio of Diameter $_{\text {Ade }}$ to Diameter $_{\text {Ref. }}$ A. Ratio of vessel diameter in response to adenosine injection (Diameter ${ }_{A d e}$ ) to diameter of the reference vessel (Diameter Ref $_{\text {) }}$ according to the test result in the overall study population; B. Ratio of Diameter Ade $_{\text {to }}$ to Diameter ${ }_{\text {Ref }}$ in Group 2 (induced spasm between 50\% and 90\%). Values are presented with median (interquartile range); $p$ values are derived by Mann-Whitney $U$ test.

\section{Ratio of Diameter Ade $_{\text {Ad }}$ to Diameter Ref}

Compared with the reference vessel diameter or the ratio of Diameter Ade $_{\text {de }}$ to Diameter Ref, vessel diameter after adenosine injection was significantly smaller in patients with spasm positive results than in those with negative results in the overall study population (median, 0.18 vs. $0.68, \mathrm{p}<0.001$ ) (Fig. 3A). A similar trend was seen for the ratio in Group 2 (median, 0.40 vs. $0.60, \mathrm{p}<0.001$ ) (Fig. 3B). The best cut-off value for the prediction of a spasm positive result was 0.505 , with a sensitivity of $96 \%$ and specificity of $92 \%$ (Fig. 4). Multivariate linear regression analysis found that current smoking (odds ratio [OR] 0.219; confidence interval [CI] 0.047-0.390) and drinking alcohol (OR 0.095; CI 0.033-0.157) were significantly associated with

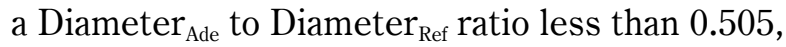
after adjusting for age, sex, investigated vessel, $\mathrm{HbA1c}$, and high sensitivity C-reactive protein.

According to available research, this is the first study investigating the effect of adenosine on ER-induced constricted coronary arteries in humans. It was demonstrated that: 1) intracoronary administration of adenosine dilated the ER-induced constricted coronary artery; 2 ) this effect was not observed in the completely occluded coronary artery in response to ER; 3) the vessel diameter after adenosine administration and its ratio to the reference vessel diameter were significantly smaller in patients with spasm positive results than in those with spasm negative results; and 4) the ratio cut-off value of 0.505 had a high sensitivity $(96 \%)$ and high specificity (92\%) in the prediction of a spasm positive result.

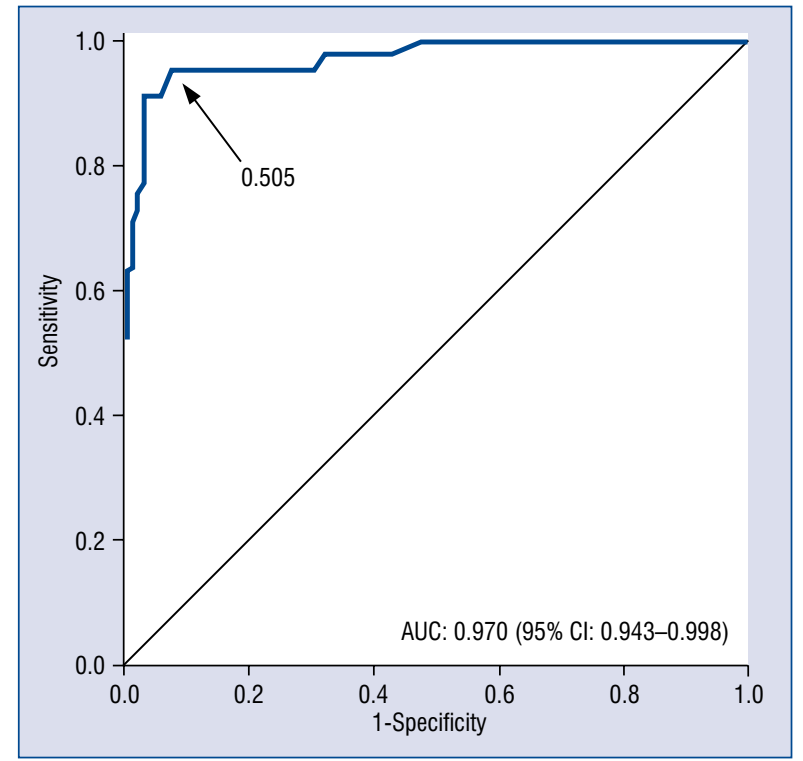

Figure 4. Receiver operating characteristics curve for Diameter $_{\text {Ade }} /$ Diameter $_{\text {Ref }}$ for the result of spasm positive. A ratio of vessel diameter in response to adenosine injection $\left(\right.$ Diameter $_{\text {Ade }}$ ) to the diameter of the reference vessel (Diameter ${ }_{\text {Ref }}$ ) of 0.505 best predicts a positive spasm result with a sensitivity of $96 \%$ and specificity of $92 \%$; AUC - area under curve; $\mathrm{Cl}$ - confidence interval.

\section{Discussion}

Coronary blood flow is regulated via changes in vessel diameter, and vascular resistance of the coronary arteries adjusts to meet the demands for myocardial oxygen $[13,17]$. This intrinsic ability 
of the heart is called autoregulation. It occurs over a wide range of coronary perfusion pressures, primarily mediated by metabolic, myogenic, and endothelial mechanisms [18]. Autoregulatory dilation occurs substantially in small coronary arterioles with diameters less than $150 \mu \mathrm{m}$, which are the major site of action of adenosine. Adenosine is a purine nucleoside produced naturally in myocardial cells from the breakdown of adenosine triphosphate during myocardial ischemia [13]. This dilation of small coronary arterioles reduces vascular resistance and decreases the pressure of upstream vessels, followed by vasodilation of larger arterioles and small arteries (140-300 $\mu$ m diameter), resulting in an increase in coronary blood flow $[17,19]$. The question is how the large epicardial coronary artery reacts toan increased blood flow. Shiode et al. [20] demonstrated that adenosine infusion $(100 \mu \mathrm{g} / \mathrm{min})$ via a $3-\mathrm{Fr}$ infusion catheter settled in the middle segment of LAD increased coronary blood flow by $+399 \%$ in 12 patients with angiographically normal coronary arteries. The proximal segment of LAD, where there was no direct contact with infused adenosine, had a larger diameter by $9.2 \%$ in response to blood flow augmentation [20]. This phenomenon is explained by flow-dependent coronary dilation. Lupi et al. [21] further validated epicardial coronary artery vasodilation with intracoronary adenosine infusion in 24 patients with angiographically normal coronary arteries. The increase in coronary diameter strongly correlated with peak coronary blood flow velocity in response to adenosine infusion, suggesting that the phenomenon was caused by a flow-mediated mechanism rather than a direct effect of adenosine [21]. A similar result was obtained with dipyridamole, which dilates epicardial coronary arteries indirectly by inhibiting intramyocardial adenosine re-uptake, provided supportive evidence of a flow-mediated mechanism. Drexler et al. [22] observed flow-dependent epicardial coronary artery dilation using papaverine. However, that response was significantly reduced in the coronary arteries with non-flow-limiting atherosclerosis, suggesting that endothelial function was involved [22]. It has been recognized that flow stimulation induces the endothelium to release endogenous vasodilators including nitric oxide, which subsequently dilates coronary arteries [23, 24]. This mechanism was supported by an observation that such flow-mediated dilation was abolished by removing the endothelium [25]. We found that intracoronary-administered adenosine dilated the epicardial coronary artery that had been vasoconstricted by ER. However, adenosine did not dilate a completely occluded epicardial coronary artery in cases where adenosine could not reach the microvessels that it acted upon to induce flow augmentation. This result supports the theory that the dilation of epicardial coronary artery is induced by a flow-dependent and endothelial mechanism rather than a direct local effect of adenosine on the epicardial artery. The response was hampered in patients with spasm positive results. Researchers previously reported that healthy endothelial function render the epicardial coronary artery more resilient to vasospasm by producing nitric oxide [26]. This data may explain the hampered response to adenosine which was observed in the patients studied herein. Furthermore, we may posit that patients with poor adenosine response, based on

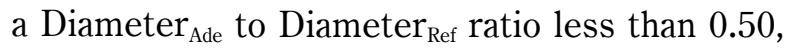
are be more prone to vasospasm.

According to the Japanese Circulation Society, a positive finding on coronary angiography is defined as a transient, total or sub-total occlusion ( $>90 \%$ stenosis) of the coronary artery [15]. However, a sizable number of patients have significant transient occlusion (> 50\% stenosis), but do not meet this criterion. In this study, $24.4 \%$ of patients in Group 2 (50-90\% stenosis) had a spasm positive result with definite ischemic ECG change. In a clinical context, a poor response of spasm-induced epicardial coronary artery to intracoronary adenosine would be a marker for vasospasm severity. It may also be an adjunctive marker to discriminate patients with vasospasm angina from those without vasospasm when ergonovine provocation shows intermediate response.

\section{Limitations of the study}

Several limitations are acknowledged in the present study. First, coronary blood flow and intracoronary pressure was not measured directly. However, it was reasonable to assume that flow would increase and pressure decrease after adenosine injection, as shown in previous studies. Second, a small number of patients were enrolled from an Asian population at a single center. Therefore, results should be confirmed in larger studies with a more diverse population. Nevertheless, the present findings add to an understanding of coronary dynamics in vasospasm.

\section{Conclusions}

The present study found that intracoronary administration of adenosine dilated the ergonovineinduced vasoconstricted epicardial coronary artery. 
However, this was not the case in a completely occluded coronary artery with induced vasospasm, suggesting that dilation was endothelial-dependent and flow-mediated. Adenosine by itself does not adequately dilate the epicardial arteries. This is of note especially during FFR manipulation and measurement, where nitroglycerin should not be overlooked.

\section{Conflict of interest: None declared}

\section{References}

1. Stern S, Bayes de Luna A. Coronary artery spasm: a 2009 update. Circulation. 2009; 119(18): 2531-2534, doi: 10.1161/CIRCULATIONAHA.108.843474, indexed in Pubmed: 19433770.

2. Radico F, Cicchitti V, Zimarino M, et al. Angina pectoris and myocardial ischemia in the absence of obstructive coronary artery disease: practical considerations for diagnostic tests. JACC Cardiovasc Interv. 2014; 7(5): 453-463, doi: 10.1016/j. jcin.2014.01.157, indexed in Pubmed: 24746648.

3. Im SIl, Choi WG, Rha SW, et al. Significant response to lower acetylcholine dose is associated with worse clinical and angiographic characteristics in patients with vasospastic angina. Korean Circ J. 2013; 43(7): 468-473, doi: 10.4070/kcj.2013.43.7.468, indexed in Pubmed: 23964293.

4. Yildirim AB, Basarici I, Kucuk M. Recurrent ventricular arrhythmias and myocardial infarctions associated with cocaine induced reversible coronary vasospasm. Cardiol J. 2010; 17(5): 512-517, indexed in Pubmed: 20865684.

5. Yamagishi M, Miyatake K, Tamai J, et al. Intravascular ultrasound detection of atherosclerosis at the site of focal vasospasm in angiographically normal or minimally narrowed coronary segments. J Am Coll Cardiol. 1994; 23(2): 352-357, indexed in Pubmed: 8294686.

6. Beltrame JF, Sasayama S, Maseri A. Racial heterogeneity in coronary artery vasomotor reactivity: differences between Japanese and Caucasian patients. J Am Coll Cardiol. 1999; 33(6): 1442-1452, indexed in Pubmed: 10334407.

7. Zaya M, Mehta PK, Merz CN. Provocative testing for coronary reactivity and spasm. J Am Coll Cardiol. 2014; 63(2): 103-109, doi: 10.1016/j.jacc.2013.10.038, indexed in Pubmed: 24201078.

8. Shin DIl, Baek SH, Her SHo, et al. The 24-month prognosis of patients with positive or intermediate results in the intracoronary ergonovine provocation test. JACC Cardiovasc Interv. 2015; 8(7): 914-923, doi: 10.1016/j.jcin.2014.12.249, indexed in Pubmed: 26003026.

9. Curry RC, Pepine CJ, Sabom MB, et al. Similarities of ergonovine-induced and spontaneous attacks of variant angina. Circulation. 1979; 59(2): 307-312, indexed in Pubmed: 103658.

10. Schroeder JS, Bolen JL, Quint RA, et al. Provocation of coronary spasm with ergonovine maleate. New test with results in 57 patients undergoing coronary arteriography. Am J Cardiol. 1977; 40(4): 487-491, indexed in Pubmed: 910712.
11. Eltzschig HK. Adenosine: an old drug newly discovered. Anesthesiology. 2009; 111(4): 904-915, doi: 10.1097/ ALN.0b013e3181b060f2, indexed in Pubmed: 19741501.

12. Cattaneo M, Schulz R, Nylander S. Adenosine-mediated effects of ticagrelor: evidence and potential clinical relevance. J Am Coll Cardiol. 2014; 63(23): 2503-2509, doi: 10.1016/j. jacc.2014.03.031, indexed in Pubmed: 24768873.

13. Layland J, Carrick D, Lee M, et al. Adenosine: physiology, pharmacology, and clinical applications. JACC Cardiovasc Interv. 2014; 7(6): 581-591, doi: 10.1016/j.jcin.2014.02.009, indexed in Pubmed: 24835328.

14. Kim J, Kim C, Kim J, et al. The eff ect of intracoronary administration of ergonovine on the contralateral coronary artery in a provocation test for the diagnosis of variant angina. Acta Cardiol. 2017; 69(6): 628-636, doi: 10.1080/ac.69.6.1000005.

15. JCS Joint Working Group. Guidelines for diagnosis and treatment of patients with vasospastic angina (Coronary Spastic Angina) (JCS 2013). Circ J. 2014; 78(11): 2779-2801, indexed in Pubmed: 25273915.

16. McGeoch RJ, Oldroyd KG. Pharmacological options for inducing maximal hyperaemia during studies of coronary physiology. Catheter Cardiovasc Interv. 2008; 71(2): 198-204, doi: 10.1002/ ccd.21307, indexed in Pubmed: 18327838.

17. Feliciano L, Henning RJ. Coronary artery blood flow: physiologic and pathophysiologic regulation. Clin Cardiol. 1999; 22(12): 775-786, indexed in Pubmed: 10626079.

18. DeFily DV, Chilian WM. Coronary microcirculation: autoregulation and metabolic control. Basic Res Cardiol. 1995; 90(2): 112-118, indexed in Pubmed: 7646415.

19. Liao JC, Kuo L. Interaction between adenosine and flowinduced dilation in coronary microvascular network. Am J Physiol. 1997; 272(4 Pt 2): H1571-H1581, doi: 10.1152/ ajpheart.1997.272.4.H1571, indexed in Pubmed: 9139938.

20. Shiode N, Morishima N, Nakayama K, et al. Flow-mediated vasodilation of human epicardial coronary arteries: effect of inhibition of nitric oxide synthesis. J Am Coll Cardiol. 1996; 27(2): 304-310, indexed in Pubmed: 8557898.

21. Lupi A, Buffon A, Finocchiaro ML, et al. Mechanisms of adenosine-induced epicardial coronary artery dilatation. Eur Heart J. 1997; 18(4): 614-617, indexed in Pubmed: 9129891.

22. Drexler $\mathrm{H}$, Zeiher AM, Wollschläger $\mathrm{H}$, et al. Flow-dependent coronary artery dilatation in humans. Circulation. 1989; 80(3): 466-474, indexed in Pubmed: 2766503.

23. Cooke JP, Rossitch E, Andon NA, et al. Flow activates an endothelial potassium channel to release an endogenous nitrovasodilator. J Clin Invest. 1991; 88(5): 1663-1671, doi: 10.1172/ JCI115481, indexed in Pubmed: 1719029.

24. Schwartz JS, Baran KW, Bache RJ. Effect of stenosis on exerciseinduced dilation of large coronary arteries. Am Heart J. 1990; 119(3 Pt 1): 520-524, indexed in Pubmed: 2309596.

25. Chu A, Chambers DE, Lin CC, et al. Effects of inhibition of nitric oxide formation on basal vasomotion and endothelium-dependent responses of the coronary arteries in awake dogs. J Clin Invest. 1991; 87(6): 1964-1968, doi: 10.1172/JCI115223, indexed in Pubmed: 2040689.

26. Kugiyama K, Yasue H, Okumura K, et al. Nitric oxide activity is deficient in spasm arteries of patients with coronary spastic angina. Circulation. 1996; 94(3): 266-271, indexed in Pubmed: 8759065 . 